\title{
Conduit choice for coronary artery bypass grafting after mediastinal radiation
}

\author{
Morgan L. Brown, MD, Hartzell V. Schaff, MD, and Thoralf M. Sundt, MD
}

Objective: Patients who have undergone prior mediastinal radiation might require coronary artery bypass grafting. However, there is some concern regarding potential radiation damage to the internal thoracic artery. Our objective was to assess the late patency of the internal thoracic artery and venous grafts in patients with prior mediastinal radiation.

Methods: Patients undergoing coronary artery bypass grafting at our clinic after prior mediastinal radiation were identified, and medical records, including operative reports, clinical notes, and coronary angiography, were reviewed.

Results: Between 1985 and 2005, 138 patients had coronary artery bypass grafting after mediastinal radiation. Of these, 25 underwent clinically indicated postoperative angiography. The mean patient age was $56.1 \pm 13.8$ years, and $24 \%$ were female. All patients received between 3000 and 6000 rads in fractionated doses. Seventy-two percent of patients had 3-vessel coronary artery disease. At late angiography (mean, 2.2 years), 6 (32\%) of 19 internal thoracic arteries and $13(27 \%)$ of 48 venous or radial arterial conduits showed stenosis of $70 \%$ or greater $(P=.72)$. Assessing only grafts that were anastomosed to the left anterior descending coronary artery, $35 \%$ (6 of 17) of internal thoracic artery grafts and 60\% (3 of 5) of non-internal thoracic artery grafts showed narrowing of $70 \%$ or greater $(P=.61)$. Among patients who received a graft to the left anterior descending coronary artery $(\mathrm{n}=113)$, however, age-adjusted survival at 5 years was superior among those receiving an internal thoracic artery graft to the left anterior descending coronary artery.

Conclusions: Internal thoracic artery graft patency among patients with prior radiation was less than expected and similar to that for venous grafts, although the effect of conduit disease versus distal target vessel runoff is unknown. Despite this, late survival was superior among those receiving an internal thoracic artery graft to the left anterior descending coronary artery. These data support use of an internal thoracic artery graft to the left anterior descending coronary artery when it appears grossly to be an acceptable conduit.

Patients who have undergone prior mediastinal radiation are at risk for early development of coronary artery disease ${ }^{1}$ and might require surgical revascularization. The preferred conduit for coronary artery bypass grafting (CABG), particularly to the left anterior descending coronary artery (LAD), is the internal thoracic artery (ITA); however, the effect of therapeutic doses of radiation on the integrity of the ITA itself is unknown. Studies regarding the late patency of irradiated ITAs are small and conflicting. ${ }^{2-13}$ We therefore retrospectively reviewed patients who had a history of mediastinal radiation and underwent $\mathrm{CABG}$ at our institution and subsequent graft angiography.

\section{MATERIALS AND METHODS \\ Patients}

Institutional review board approval was obtained. Patients who received large doses of radiation (3000-6000 rads) to the mediastinum before cardiac operation were identified from institutional databases. Patients who received only neck, spine, or tangential radiation for breast cancer were excluded. Be-

\footnotetext{
From the Division of Cardiovascular Surgery, Mayo Clinic, Rochester, Minn. Received for publication Nov 25, 2007; revisions received June 4, 2008; accepted for publication July 3, 2008.

Address for reprints: Thoralf M. Sundt, MD, Mayo Clinic, 200 1st St SW, Rochester, MN 55905 (E-mail: sundt.thoralf@mayo.edu).

J Thorac Cardiovasc Surg 2008;136:1167-71

$0022-5223 / \$ 34.00$

Copyright (C) 2008 by The American Association for Thoracic Surgery

doi:10.1016/j.jtcvs.2008.07.005
}

tween 1985 and 2005, 138 patients were identified with a history of previous mediastinal radiation and CABG. After review of clinical information from the medical record, $25(18 \%)$ patients underwent follow-up angiography. In all cases angiography was performed for clinical indications, including chest pain or shortness of breath.

\section{Surgical Approach}

Although there is no policy at our institution regarding patients with mediastinal radiation therapy in general, the ITA is preferred as the conduit of choice to the LAD. After median sternotomy, ITAs were harvested by using a pedicled technique and grossly inspected for patency. If the ITA did not appear to have adequate blood flow or was fibrotic, the artery was ligated, and venous or radial arterial conduits were used as bypass conduits. It has not been the practice in our institution to assess the ITAs preoperatively for patency during coronary artery catheterization. Intraoperative graft flow measurements were not performed. At the time of the operation, concomitant procedures were performed as indicated.

\section{Statistical Analysis}

Continuous variables are expressed as means and standard deviations or medians and ranges. Groups were compared by using $t$ tests or $\chi^{2}$ tests, as appropriate. Vital status for all patients was attained through use of Accurint (www.accurint.com) and the Social Security Death Index. Kaplan-Meier survival curves were created with SAS version 9.1 (SAS Institute, Inc, Cary, NC) and compared with a log-rank test.

\section{RESULTS}

Of the 138 patients undergoing $\mathrm{CABG}$ after mediastinal radiation, $51 \%$ were female, and the mean age was $63 \pm 13$ 


\section{Abbreviations and Acronyms \\ $\mathrm{CABG}=$ coronary artery bypass grafting \\ ITA $=$ internal thoracic artery \\ LAD $=$ left anterior descending coronary artery}

years. The most common reasons for mediastinal radiation included breast cancer (40\%), lymphomas (including Hodgkin's and non-Hodgkin's lymphoma: 34\%), germ cell tumors $(9 \%)$, lung cancers $(8 \%)$, and others (thymic, esophageal, and laryngeal: $9 \%$ ).

\section{Patients With Follow-up Angiography}

Of the 25 patients who had follow-up angiography, a lower percentage were female $(24 \%)$, and the patients were younger when compared with the entire cohort (Table 1). The most common reasons for radiation therapy were similar (52\% lymphoma, 24\% germ cell cancer, and 20\% breast cancer). The median time from radiation exposure to CABG was 23.1 years (range, 2.1-40.3 years) for the angiography group. Fifteen patients had a history of hypertension, 17 patients had hyperlipidemia, 12 patients were previous or current smokers, and 4 patients had diabetes (Table 2). Twenty-one (84\%) of the patients were in New York Heart Association class III or IV, and the mean ejection fraction was $56 \% \pm 12 \%$.

Among those patients undergoing postoperative angiography, the majority $(72 \%)$ had 3-vessel disease, and the average number of distal anastomoses per patient was 2.6 versus $2.4(P=.33)$ in those patients who did not have follow-up angiography. Conduit selection was similar between the angiography group and the whole group. Among the angiography group $(n=25)$, there were 19 ITAs used (16 left and 3 right), 2 radial arteries, and 46 vein grafts. Sixteen ITA grafts and 5 vein grafts were anastomosed to the LAD. Concomitant procedures were performed in 9 patients, including aortic valve replacement $(n=6)$, mitral valve replacement $(n=1)$, mitral valve repair $(n=1)$, pericardiectomy $(n=1)$, and septal myectomy $(\mathrm{n}=1)$.

The median time from operation to angiography was 2.2 years (range, $0.5-10.3$ years). Angiograms were performed for clinical indications, including symptoms or positive noninvasive test results. In the ITA grafts, 4 were completely occluded, leaving $15(79 \%)$ of 19 patent. Of these, 9 ITA grafts were perfectly patent, 4 had narrowing of less than $70 \%$, and 2 were narrowed by $70 \%$ or more. Analysis of other conduits, both radial arteries and vein grafts, revealed that 13 grafts were completely occluded, resulting in $36(73 \%)$ of 48 patent grafts. This included 12 that were perfectly patent, 19 that showed less than $70 \%$ stenosis, and 5 that showed $70 \%$ or greater stenosis. Late patency on angiography was not significantly different between ITA grafts and venous
TABLE 1. Preoperative and operative characteristics of the entire cohort of patients with prior mediastinal radiation

\begin{tabular}{|c|c|c|c|}
\hline Patient characteristics & $\begin{array}{l}\text { Patients with } \\
\text { follow-up } \\
\text { angiography } \\
(\mathbf{n}=\mathbf{2 5})\end{array}$ & $\begin{array}{c}\text { Patients } \\
\text { without } \\
\text { follow-up } \\
\text { angiography } \\
(\mathrm{n}=113)\end{array}$ & $P$ value \\
\hline Mean age (y) & $56 \pm 13$ & $64 \pm 13$ & .007 \\
\hline Female sex $(\%)$ & $6(24)$ & $65(58)$ & .002 \\
\hline History of smoking $(\%)$ & $12(48)$ & $61(54)$ & .588 \\
\hline History of diabetes $(\%)$ & $4(16)$ & $24(21)$ & .556 \\
\hline $\begin{array}{l}\text { History of } \\
\quad \text { hypercholesterolemia }(\%)\end{array}$ & $17(68)$ & $74(65)$ & .810 \\
\hline History of hypertension & $15(52)$ & $63(58)$ & .698 \\
\hline $\begin{array}{l}\text { New York Heart Association } \\
\text { class III/IV }(\%)\end{array}$ & $21(84)$ & $88(78)$ & .288 \\
\hline Mean ejection fraction $(\%)$ & $56 \pm 12$ & $57 \pm 13$ & .212 \\
\hline Isolated bypass procedure $(\%)$ & $17(68)$ & $63(56)$ & .262 \\
\hline $\begin{array}{l}\text { Mean no. of distal } \\
\text { anastomoses }\end{array}$ & $2.6 \pm 1.2$ & $2.4 \pm 1.0$ & .333 \\
\hline ITA use (no. of patients, \%) & $18(72)$ & $65(58)$ & \\
\hline Left ITA & 15 & 59 & .731 \\
\hline Right ITA & 2 & 4 & .298 \\
\hline Bilateral ITA & 1 & 2 & .454 \\
\hline $\begin{array}{l}\text { Radial artery use (no. of } \\
\text { patients, \%) }\end{array}$ & $2(8)$ & $4(4)$ & .298 \\
\hline \multicolumn{4}{|l|}{ Venous distal anastomoses } \\
\hline 1 & 4 & 27 & .392 \\
\hline 2 & 9 & 44 & .237 \\
\hline 3 & 8 & 26 & .345 \\
\hline 4 & 0 & 1 & 1.000 \\
\hline
\end{tabular}

grafts $(P=.44)$. Assessing only grafts that were anastomosed to the LAD, $32 \%$ of ITA grafts and $60 \%$ of the non-ITA grafts showed stenosis of $70 \%$ or greater $(P=.61)$.

\section{Patients With Grafts to the LAD}

We selected all patients who had a graft to the LAD $(n=$ $113,82 \%$ ). Patients did not receive an ITA graft to the LAD $(n=34)$ for several reasons: 10 were fibrotic or scarred, 4 were not used because the patient's condition was unstable, 2 had prior injury to the ITA, 2 had a known ITA stenosis on angiography, 1 had poor pulsations, 1 was of inadequate length, and 1 had tumor-positive tissue around the ITA. In 13 patients there was inadequate documentation to determine the reason why the ITA was not used.

Late survival was compared between patients who had an ITA graft $(\mathrm{n}=79)$ and those who had a venous graft $(\mathrm{n}=$ 34 ) to the LAD. At 1 and 5 years, the age-adjusted survivals of patients with an ITA graft to the LAD were $89 \%$ and $67 \%$ compared with $80 \%$ and $51 \%$ in patients with a venous graft to the LAD, respectively $(P=.16$, Figure 1$)$. When all patients who received a graft to the $\operatorname{LAD}(\mathrm{n}=113)$ were compared with an age- and sex-matched population, the overall survival was decreased $(P<.001$, Figure 2$)$. 
TABLE 2. Characteristics of patients who had follow-up angiography available

\begin{tabular}{|c|c|c|c|c|c|c|c|c|c|}
\hline Patient no. & Age at operation (y) & $\mathbf{M} / \mathbf{F}$ & Year of radiation & Cancer type & $\uparrow \mathbf{B P}$ & Smoking Hx & DM & $\uparrow$ Lipids & NYHA class \\
\hline 1 & 57 & $\mathrm{M}$ & 1968 & Sarcoma & No & No & No & No & 2 \\
\hline 2 & 62 & $\mathrm{M}$ & 1986 & Hodgkin's & No & Yes & No & No & 3 \\
\hline 3 & 61 & $\mathrm{M}$ & 1986 & Hodgkin's & No & No & Yes & No & 3 \\
\hline 4 & 39 & $\mathrm{M}$ & 1980 & Non-Hodgkin's & Yes & No & No & No & 3 \\
\hline 5 & 71 & $\mathrm{~F}$ & 1955 & Breast (L) & Yes & No & No & No & 3 \\
\hline 6 & 76 & $\mathrm{~F}$ & 1984 & Breast (L) & No & No & No & Yes & 4 \\
\hline 7 & 39 & $\mathrm{M}$ & 1969 & Hodgkin's & No & No & No & Yes & 3 \\
\hline 8 & 45 & M & 1976 & Hodgkin's & No & No & No & No & 2 \\
\hline 9 & 48 & $\mathrm{M}$ & 1964 & Hodgkin's & Yes & Yes & Yes & Yes & 2 \\
\hline 10 & 49 & $\mathrm{M}$ & 1976 & Germ cell & Yes & Yes & No & Yes & 4 \\
\hline 11 & 39 & $\mathrm{M}$ & 1974 & Hodgkin's & Yes & No & No & No & 4 \\
\hline 12 & 46 & M & 1967 & Hodgkin's & No & Yes & No & Yes & 3 \\
\hline 13 & 57 & M & 1986 & Germ cell & No & Yes & No & Yes & 3 \\
\hline 14 & 47 & $\mathrm{M}$ & 1970 & Hodgkin's & No & Yes & No & Yes & 4 \\
\hline 15 & 67 & $\mathrm{~F}$ & 1969 & Breast (R) & Yes & No & Yes & Yes & 3 \\
\hline 16 & 37 & $\mathrm{M}$ & 1976 & Hodgkin's & Yes & Yes & No & Yes & 3 \\
\hline 17 & 58 & $\mathrm{M}$ & 1975 & Germ cell & Yes & No & No & Yes & 4 \\
\hline 18 & 64 & $\mathrm{M}$ & 1967 & Hodgkin's & Yes & Yes & No & Yes & 2 \\
\hline 19 & 60 & $\mathrm{~F}$ & 1960 & Germ Cell & Yes & Yes & No & Mo & 4 \\
\hline 20 & 46 & M & 1970 & Non-Hodgkin's & No & No & No & Yes & 4 \\
\hline 21 & 89 & $\mathrm{~F}$ & 1992 & Breast (R) & No & No & No & Yes & 3 \\
\hline 22 & 53 & $\mathrm{M}$ & 1965 & Non-Hodgkin's & No & Yes & No & Yes & 3 \\
\hline 23 & 63 & M & 1963 & Seminoma & Yes & No & No & Yes & 4 \\
\hline 24 & 76 & $\mathrm{~F}$ & 2002 & Breast (L) & Yes & Yes & Yes & Yes & 4 \\
\hline 25 & 62 & M & 1980 & Seminoma & Yes & Yes & No & Yes & 4 \\
\hline
\end{tabular}

$M$, Male; $F$, female; $B P$, blood pressure; $H x$, history; $D M$, diabetes mellitus; NYHA, New York Heart Association; $L$, left; $R$, right.

\section{DISCUSSION}

Patients with prior mediastinal radiation can present with myocardial, pericardial, valvular, and coronary artery disease. Radiation can cause damage to the vasculature through direct damage to the endothelial cells. ${ }^{1}$ Fibrous proliferation can then occur, resulting in a loss of parenchymal cells. ${ }^{2}$ In patients who have medical conditions that also affect the

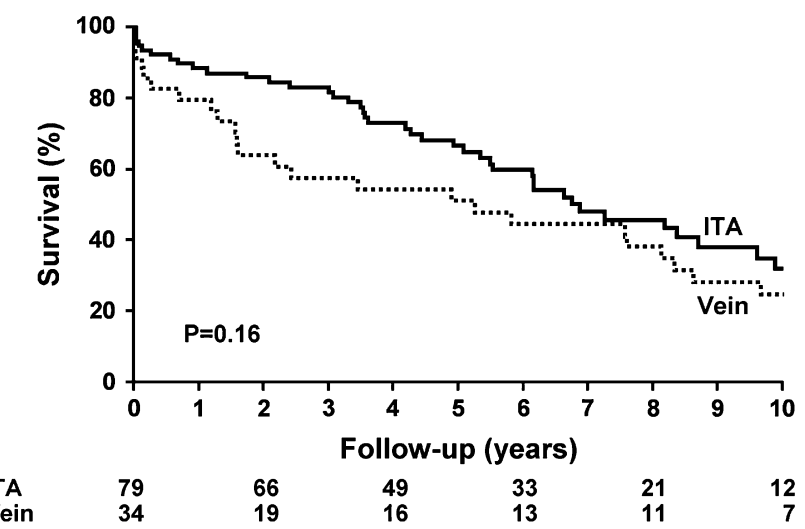

FIGURE 1. Age-adjusted survival compared between patients with prior mediastinal radiation therapy who received an internal thoracic artery (ITA) graft compared with a venous graft to the left anterior artery. This age-adjusted comparison demonstrates superior survival in patients who received an internal thoracic artery graft, but overall, it was not statistically significant. vascular system, such as hypertension or diabetes, radiation damage to vessels can be greater in severity. ${ }^{2}$ When CABG surgery is required, the choice of bypass conduit presents an additional challenge. The ITA is the preferred conduit in most circumstances, with 5-year patency rates in contemporary series for nonirradiated ITA grafts as high as $96 \%$ to $98 \%$ in comparison with venous grafts as low as $83 \%$ to

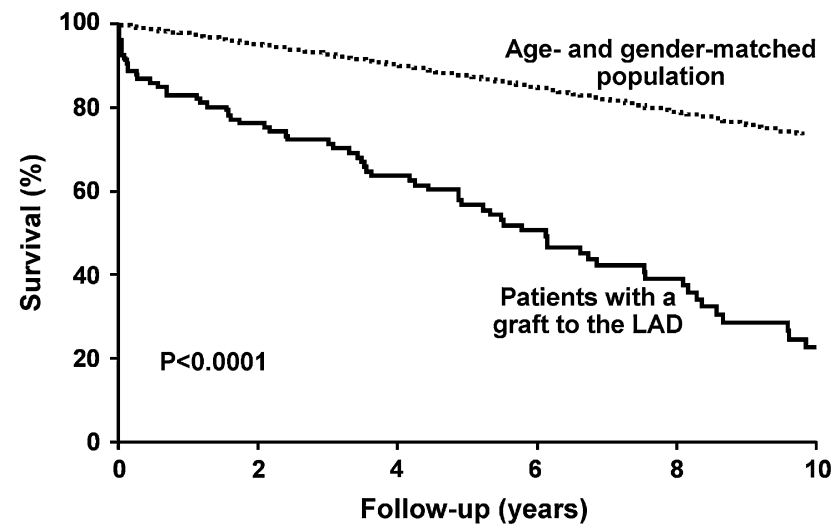

FIGURE 2. Survival of patients who had prior mediastinal radiation therapy and had either an internal thoracic artery or vein grafted to the left anterior descending coronary artery $(L A D ; \mathrm{n}=113)$. When compared with an age- and sex-matched Minnesota population, patients who had prior mediastinal radiation therapy had a significantly reduced late survival. 
$95 \% .^{14,15}$ The effect of radiation vasculopathy on the ITA, however, is uncertain.

Prior literature on the subject is divided. A study from Nasso and colleagues ${ }^{3}$ suggested that irradiated skeletonized ITAs have equal patency as saphenous veins and other arterial conduits. Other authors have also supported the use of the ITA in these patients with prior mediastinal radiation exposure $^{4-9}$; however, others have suggested that mediastinal radiation might damage the ITA, causing either fragility or leading to early graft failure if it is used as a conduit. ${ }^{10-13}$ Several of these studies ${ }^{10-12}$ are case reports, but in the study by Hicks, ${ }^{13}$ the ITA was only usable as a graft in 3 of 14 patients with previous mediastinal radiation exposure because of friability and fibrosis.

A previous study from our institution ${ }^{16}$ suggested that because of the unknown quality of the ITA graft and the increased risk of mediastinal wound complications in patients with previous mediastinal radiation therapy, alternative conduits should be considered. Despite these concerns, because of the well-documented effect of an ITA graft to the LAD on late survival, ${ }^{17}$ it has been our strong institutional bias to use the ITA conduit when possible. Indeed, in this series 79 $(70 \%)$ of 113 patients with significant LAD disease received an ITA graft. The argument to use the ITA is particularly compelling because these patients are often young. Furthermore, with concerns about small-vessel disease and the adequacy of distal runoff, the ITA is an appealing conduit. This provided us with a sizeable population from which to draw survival data. Unfortunately, only a small minority underwent postoperative coronary angiography.

Preoperative assessment of the ITA might be a consideration, although it has not been our practice up to now. Van Son and coworkers ${ }^{4}$ and others ${ }^{6,7}$ suggest that if the patency is ascertained preoperatively, the ITA can be safely used. In general, patients in this study did not have examination of the ITA on angiography before surgical revascularization unless subclavian steal was suspected. All ITA grafts were grossly inspected at time of surgical intervention for patency.

In this study, graft patency after CABG in patients with prior mediastinal radiation therapy was lower than anticipated for patients without radiation therapy. Explanations might include greater severity of native coronary artery disease and poor distal arterial run-off caused by radiation damage. Radiation might also cause intimal injury to the ITA, although in a recent report irradiated ITAs had similar amounts of fibrosis on histomorphologic examination when compared with nonirradiated ITAs. ${ }^{9}$ Another important factor in understanding overall graft patency is that patients underwent symptom-directed angiography rather than routine catheterization. Buxton and associates ${ }^{18}$ have previously shown that symptom-directed graft failure rates might be as much as double those of an asymptomatic group (17\% vs $9 \%$ in the ITA at 5 years, $P=.002$ ). There are few data published on graft patency in patients with prior mediastinal radiation because prior studies used both clinical and noninvasive follow-up. ${ }^{3,4}$

Age-adjusted survival was superior among patients who had an ITA graft to the LAD when compared with those who had a venous graft, although this was not statistically significant. This is likely highly susceptible to selection bias because in most cases the ITA was considered for use unless it appeared fibrotic or had poor flow. In addition, it is also possible that surgeons have a preference for placing ITA grafts in healthier patients. Our study reports a somewhat lower survival than our previously reported 5-year survival of $73 \%$ for patients undergoing CABG after previous mediastinal radiation. ${ }^{16}$ In the current series, however, we included patients who had concomitant valvular heart disease that might indicate a poorer prognosis. ${ }^{19}$

Finally, it must be acknowledged that our study might simply be underpowered to detect a difference between the patency of an ITA or venous conduit. In addition, we did not have adequate patient numbers to assess the effect of the radial artery in this cohort.

\section{CONCLUSION}

Irradiated ITA grafts had similar patency rates to venous or radial arterial conduits. Either ITA grafts or venous conduits can be used in patients who have received previous mediastinal radiation. However, when patent, these data suggest the ITA graft remains the conduit choice for grafting to the LAD in patients with prior mediastinal radiation therapy.

\section{References}

1. Schultz-Hector S, Trott KR. Radiation-induced cardiovascular diseases: is the epidemiologic evidence compatible with the radiobiologic data? Int J Radiat Oncol Biol Phys. 2007;67:10-8.

2. Baker DG, Krochak RJ. The response of the microvascular system to radiation: a review. Cancer Invest. 1989;7:287-94.

3. Nasso G, Canosa C, De Filippo M, Mondugno P, Anselmi A, Gaudino M, et al. Thoracic radiation therapy and suitability of internal thoracic arteries for myocardial revascularization. Chest. 2005;128:1587-92.

4. Van Son JA, Noyez L, van Asten WN. Use of internal mammary artery in myocardial revascularization after mediastinal irradiation. J Thorac Cardiovasc Surg. 1992;104:1539-44.

5. Gharagozloo F, Clements IP, Mullany CJ. Use of the internal mammary artery for myocardial revascularization in a patient with radiation-induced coronary artery disease. Mayo Clin Proc. 1992;67:1081-4.

6. Reber D, Birnbaum DE, Tollenaere P. Heart diseases following mediastinal irradiation: surgical management. Eur J Cardiothorac Surg. 2005;9:202-5.

7. Fuzellier JF, Mauran P, Metz D. Radiation-inducted bilateral coronary ostial stenosis in a 17-year-old patient. J Card Surg. 2006;21:600-2.

8. Gansera B, Haschemi A, Angelis I, Eichinger W, Breuer M, Keiditsch E, et al. Cardiac surgery in patients with previous carcinoma of the breast and mediastinal irradiation: is the internal thoracic artery graft obsolete? Thorac Cardiovasc Surg. 1999;47:376-80.

9. Gansera B, Schmidtler F, Angelis I, Botzenhardt F, Schuster T, Kiask T, et al. Quality of internal thoracic artery grafts after mediastinal irradiation. Ann Thorac Surg. 2007;84:1479-84

10. Schulman HE, Korr KS, Myers TJ. Left internal thoracic artery graft occlusion following mediastinal radiation therapy. Chest. 1994;105:1881-2.

11. Hanet C, Marchand E, Keyex A. Left internal mammary artery occlusion after mastectomy and radiotherapy. Am J Cardiol. 1990;65:1044-5. 
12. Renner S, Massel D, Moon BC. Mediastinal irradiation: a risk factor for atherosclerosis of the internal thoracic arteries. Can J Cardiol. 1999;15: 597-600.

13. Hicks GL Jr. Coronary artery operation in radiation-associated atherosclerosis: long-term follow-up. Ann Thorac Surg. 1992;53:670-4.

14. Tatoulis J, Buxton BF, Fuller JA. Patencies of 2127 arterial to coronary conduits over 15 years. Ann Thorac Surg. 2004;77:93-101.

15. Hayward PA, Buxton BF. Contemporary coronary graft patency: 5-year observational data from a randomized trial of conduits. Ann Thorac Surg. 2007;84:795-9.

16. Handa N, McGregor CGA, Danielson GK, Orszulak TA, Mullany CJ, Daly $\mathrm{RC}$, et al. Coronary artery bypass grafting in patients with previous mediastinal radiation therapy. $J$ Thorac Cardiovasc Surg. 1999;117: 1136-43.

17. Loop FD, Lytle BW, Cosgrove DM, Stewart RW, Goormaster M, Williams GW, et al. Influence of the internal-mammary-artery graft on 10-year survival and other cardiac events. N Engl J Med. 1986;314:1-6.

18. Buxton BF, Durairaj M, Hare DL, Gordon I, Moten S, Orford V, et al. Do angiographic results from symptom-directed studies reflect true graft patency? Ann Thorac Surg. 2005;80:896-901.

19. Handa N, McGregor CG, Danielson GK, Daly RC, Dearani JA, Mullany CJ, et al. Valvular heart operation in patients with previous mediastinal radiation therapy. Ann Thorac Surg. 2001;71:1880-4. 